FEDERAL RESERVE BANK OF SAN FRANCISCO

WORKING PAPER SERIES

\title{
Global Current Account Adjustment: A Decomposition
}

\author{
Michael B. Devereux \\ University of British Columbia and CEPR \\ Amartya Lahiri \\ University of British Columbia \\ Ke Pang \\ University of British Columbia
}

May 2006

Working Paper 2006-40

http://www.frbsf.org/publications/economics/papers/2006/wp06-40bk.pdf

The views in this paper are solely the responsibility of the authors and should not be interpreted as reflecting the views of the Federal Reserve Bank of San Francisco or the Board of Governors of the Federal Reserve System. This paper was produced under the auspices for the Center for Pacific Basin Studies within the Economic Research Department of the Federal Reserve Bank of San Francisco. 


\title{
Global Current Account Adjustment: A Decomposition ${ }^{1}$
}

\author{
Michael B. Devereux \\ AMARTYA LAHIRI \\ University of British Columbia and CEPR University of British Columbia \\ Ke PANG \\ University of British Columbia \\ First version: May 2006 \\ Extremely Preliminary
}

${ }^{1}$ Devereux and Lahiri would like to thank SSHRC for research support. 


\begin{abstract}
The rising current account deficit in the USA has attracted considerable attention in recent years. We use the "business cycle accounting" methodology to identify the principal distortions that have affected the external accounts of the US. In particular, we measure distortions in the optimality conditions of a simple two-country general equilibrium model using data from the US and the other G7 countries. We then feed these measured distortions into the model individually and use the simulated counterfactual paths of the current account to determine the contribution of each of these "wedges" to the overall external imbalance of the USA. We find that no single wedge in isolation can account closely for the observed current account. However, a combination of productivity differences and deviations from risk-sharing between the US and the rest of the G7 does the best job in accounting for most of the measured movement of the US current account.
\end{abstract}




\section{Introduction}

In the last five years the international macroeconomics literature has become increasingly concerned with global current account imbalances, with particular focus on the size and persistence of the US current account deficit. There is some irony here, given that until recently one of the greater challenges facing the profession was to provide a coherent explanation of the Feldstein-Horioka puzzle, which noted that current account imbalances were of a far smaller magnitude than theory suggests. The unifying logic behind both approaches however has been the need to converge on a reasonable way of quantifying the size of efficient international capital movements. An answer to this question is a critical pre-requisite for understanding the degree of current account sustainability, and for making predictions regarding future trends in current account balances.

While much of the recent literature on global imbalances (e.g. Caballero, Gourinchas and Fahri, 2005, Engel and Rogers, 2005 ) has attempted to rationalize the recent surge in the US current account deficit within theoretical settings, there has been little effort devoted to providing a quantitative accounting of the observed path of capital flows. One way of addressing this accounting question would involve answering the question; can the path of capital flows both before and after the recent surge in global imbalances be reconciled within a model wherein both savings and investment are determined by standard neoclassical principles? In this paper we attempt to answer precisely this question.

We follow the recent methodology developed by Cole and Ohanian (2004, 2005), Chari et al (2004), Mulligan (2004) etc. In particular, we construct a model of the world economy comprised of two regions - the US and the rest of the G7. The model is the standard one-sector neoclassical growth model with production and investment. The first-order-conditions of the model are standard; for each country there is an optimal labor-leisure choice condition and an intertemporal Euler equation which dictates optimal savings behavior in the model. In addition, there is a cross-country risk-sharing condition. We then run actual data over the sample period 1970-2004 through the 
optimality conditions of the model and back out the ex-post deviations in these condition relative to optimality. We call these measured deviations "wedges" In addition to the measured wedges in the first-order-conditions, we also compute measured total factor productivity in each region and call that it the productivity wedge. Finally, because the G7 is not a closed economy, it is necessary to account for the gap between expenditure and income, i.e. net exports for the G7 as a whole. We represent this as a 'resource constraint wedge'. Thus, our model generates eight wedges - five optimality wedges, or deviations from model's necessary conditions, two productivity wedges, and a resource constraint wedge. As shown by Chari et al (2004), all differences in macroeconomic outcomes across the two regions arise due to these wedges, i.e., the wedges jointly account for all the differences across regions. Hence, this approach allows us to decompose the regional differences into eight components.

Having extracted the individual wedges in this manner, we can separately introduce the wedges in the model one by one, and in combinations, treating them as exogenous shocks. The key question is which wedge or combination of wedges does the best job of representing the sample path for the US current account. By studying the artificial sample paths of the current account produced by individual wedges, we can throw light on the value of different theoretical approaches to explaining the current account. For instance, if, as is often argued, the US current account deficit is a reflection of higher recent underlying productivity growth in the US, this would imply that the TFP wedge should play a dominant role in accounting for the sample path of the current account. On the other hand, if the current account is simply a refection of a trend fall in US savings, independent of the path of TFP, then this would be represented in our model by leading role for a combination of two wedges in the inter-temporal optimality conditions of the model (as shown below, the 'risk sharing wedge', and the 'Euler equation wedge').

While our results are still preliminary, perhaps the most clear conclusion we can reach is a slightly negative one. According to the accounting, there is no mono-causal representation for the 
sample path of the US current account over this period. In particular, neither TFP wedges nor risksharing wedges alone, when fed into the model as independent shocks, can give a close representation of the current account. But together these two wedges provide quite a good explanation for the current account over most of the sample period. The only caveat is that the recent sharp downturn in the current account is not well explained by these two wedges. In fact, to give an adequate representation of the current account, including the recent downturn, requires a combination of multiple wedges. Another implication of the accounting is that 'Euler equation wedges' alone do a very poor job in explaining the sample path, although a combination of Euler equations and risk sharing wedges, even without the TFP wedge, provide quite a good representation. Clearly further work needs to be done..

The next section lays out the baseline structure and our measurement of the "wedges". In Section 3 we do the data accounting exercise so that the model, when simulated with all the measured wedges, replicates the data. Section 4 conducts the counterfactual exercises while the last section concludes.

\section{The Model}

We consider the basic one good, two-country open economy model. We label the two countries Home and Foreign. At every date $t$ Home and Foreign are inhabited by $N_{t}$ and $N_{t}^{*}$ identical agents. The lifetime welfare of each agent at Home is given by:

$$
V_{0}=\sum_{t=0}^{\infty} \beta^{t} u\left(c_{t}, 1-l_{t}\right)=\sum_{t=0}^{\infty} \beta^{t}\left(\frac{z_{t}^{1-\sigma}-1}{1-\sigma}\right)
$$

where

$$
z_{t}=c_{t}^{\eta}\left(1-l_{t}\right)^{1-\eta}
$$

$c$ is consumption and $l$ denotes the fraction of time devoted to work. Preferences are identical across countries so there is an identical utility function for Foreign residents. 
Output of the single good in both countries is produced using an identical production technology which uses capital and labor:

$$
Y=K^{\alpha}(a N l)^{1-\alpha}
$$

where $K$ is aggregate physical capital, $N$ is total population and $a$ denotes labor augmenting productivity. There is a corresponding production technology for output abroad which takes as inputs $K^{*}$ and $a^{*} N^{*} l^{*}$. Note that per capita output at Home can be written as

$$
y=k^{\alpha}(a l)^{1-\alpha}
$$

where $y=Y / N$ and $k=K / N$.

In terms of notational convention, throughout the paper we shall denote all Foreign variables with stars. Variables with capital letters denote aggregate variables, lower case letters denote per capita variables $\left(x=\frac{X}{N}\right)$, and lower case letters with tildes on top denote variables per efficiency units of labor $\left(\tilde{x}=\frac{X}{a N l}\right)$.

Capital accumulates at Home according to

$$
K_{t+1}=K_{t}\left[\left(\frac{I_{t}}{K_{t}}\right)^{\theta}+1-\delta\right], \quad \theta \in(0,1] .
$$

where $I$ denotes gross investment while $\delta$ is the rate depreciation. Thus, we are allowing for adjustment costs in the capital accumulation process whenever $\theta<1$. The capital accumulation equation can be rewritten in per capita terms as

$$
N_{t+1} k_{t+1}=N_{t} k_{t}\left[\left(\frac{i_{t}}{k_{t}}\right)^{\theta}+1-\delta\right]
$$

Similarly, for Foreign we have:

$$
N_{t+1}^{*} k_{t+1}^{*}=N_{t}^{*} k_{t}^{*}\left[\left(\frac{i_{t}^{*}}{k_{t}^{*}}\right)^{\theta}+1-\delta\right]
$$

There is a government in each country which consumes $G_{t}$ and $G_{t}^{*}$ in period $t$. We model government consumption as a share of total output so that

$$
G_{t}=s_{t} Y_{t}
$$


A corresponding equation holds for Foreign.

The aggregate resource constraint for the world dictates that total private consumption plus total investment plus total public consumption in Home and Foreign must equal total world output. Hence,

$$
N_{t}\left(c_{t}+i_{t}\right)+N_{t}^{*}\left(c_{t}^{*}+i_{t}^{*}\right)=N_{t}\left(1-s_{t}\right) k_{t}^{\alpha}\left(a_{t} l_{t}\right)^{1-\alpha}+N_{t}^{*}\left(1-s_{t}^{*}\right) k_{t}^{* \alpha}\left(a_{t}^{*} l_{t}^{*}\right)^{1-\alpha}
$$

We set up the problem as a planning problem. In particular, the social planner maximizes:

$$
V=\sum_{t=0}^{\infty} \beta^{t}\left[N_{t} u\left(c_{t}, 1-l_{t}\right)+N_{t}^{*} u\left(c_{t}^{*}, 1-l_{t}^{*}\right)\right]
$$

subject to equations (1), (2) and (3). We choose to set up the problem in this way because our primary goal here is to identify the sources of deviations from the benchmark frictionless paradigm. The planning problem provides the frictionless paradigm. ${ }^{1}$

The first-order conditions for this problem are:

$$
\begin{gathered}
u_{c}\left(c_{t}, 1-l_{t}\right)=u_{c}\left(c_{t}^{*}, 1-l_{t}^{*}\right) \\
\frac{u_{l}\left(c_{t}, 1-l_{t}\right)}{u_{c}\left(c_{t}, 1-l_{t}\right)}=a_{t}(1-\alpha) \tilde{k}_{t}^{\alpha} \\
\frac{u_{l}\left(c_{t}^{*}, 1-l_{t}^{*}\right)}{u_{c}\left(c_{t}^{*}, 1-l_{t}^{*}\right)}=a_{t}^{*}(1-\alpha) \tilde{k}_{t}^{* \alpha} \\
\frac{u_{c}\left(c_{t}, 1-l_{t}\right)}{\beta u_{c}\left(c_{t+1}, 1-l_{t+1}\right)}=\frac{\theta \alpha \tilde{k}_{t+1}^{\alpha-1}+\left(\frac{i_{t+1}}{k_{t+1}}\right)^{1-\theta}\left\{(1-\theta)\left(\frac{i_{t+1}}{k_{t+1}}\right)^{\theta}+1-\delta\right\}}{\left(\frac{i_{t}}{k_{t}}\right)^{1-\theta}} \\
\frac{u_{c}\left(c_{t}^{*}, 1-l_{t}^{*}\right)}{\beta u_{c}\left(c_{t+1}^{*}, 1-l_{t+1}^{*}\right)}=\frac{\theta \alpha \tilde{k}_{t+1}^{* \alpha-1}+\left(\frac{i_{t+1}^{*}}{k_{t+1}^{*}}\right)^{1-\theta}\left\{(1-\theta)\left(\frac{i_{t+1}^{*}}{k_{t+1}^{*}}\right)^{\theta}+1-\delta\right\}}{\left(\frac{i_{t}^{*}}{k_{t}^{*}}\right)^{1-\theta}}
\end{gathered}
$$

\footnotetext{
${ }^{1}$ Note that we could have instead set up the decentralized problem with firms in each country choosing inputs, households choosing labor supply and their portfolio allocation between domestic capital, domestic real bonds and foreign real bonds, and governments financing their consumption needs through lump-sum taxes. That decentralized problem would induce identical allocations to the planning problem we analyze here.
} 
These conditions are standard. Equation (4) says that without frictions in asset trade, and with identical goods, the marginal utility from consumption should be equated across countries. Equations (5) and (2) determine the optimal labor-leisure allocations in Home and Foreign respectively. Equations (7) and (8) determine optimal saving and investment in the two countries.

\subsection{Measuring "Wedges"}

The point of the exercise here is to determine the degree to which these optimality conditions of the frictionless paradigm are rejected by the data. This would then provide an identification of the source and magnitude of the distortions that characterized these economies during the period under study. We measure these violations of the optimality conditions by computing the ratios of the left hand side (LHS) to the right hand side (RHS) of each first order condition of the model. We call these ratios "wedges". If the first order conditions of the model were to hold exactly then all these wedges would equal one. To the extent that they deviate from unity, the wedges identify the key distortions affecting the economy. At the same time, the characteristics of the wedges that the model produces give us some pointers as to the nature of a more elaborate model that may need to be constructed in order to provide a full theory of current account behavior.

Since there are five first order conditions we have five corresponding wedges:

$$
\begin{gathered}
\frac{\left(\frac{\tilde{c}_{t}}{\tilde{c}_{t}^{*}}\right)^{\eta(1-\sigma)-1}\left(\frac{1-l_{t}}{1-l_{t}^{*}}\right)^{(1-\eta)(1-\sigma)}\left(\frac{l_{t}}{l_{t}^{*}}\right)^{\eta(1-\sigma)-1}}{\left(\frac{a_{t}^{*}}{a_{t}}\right)^{\eta(1-\sigma)-1}}=w r s_{t} \\
\frac{\left(\frac{1-\eta}{\eta}\right) \frac{\tilde{c}_{t}}{\left(1-l_{t}\right) / l_{t}}}{(1-\alpha) \tilde{k}_{t}^{\alpha}}=w i t a_{t} \\
\frac{\left(\frac{1-\eta}{\eta}\right) \frac{\tilde{c}_{t}^{*}}{\left(1-l_{t}^{*}\right) / l_{t}^{*}}}{(1-\alpha) \tilde{k}_{t}^{* \alpha}}=w i t a_{t}^{*} \\
\frac{\frac{1}{\beta}\left(\frac{\tilde{c}_{t+1}}{\tilde{c}_{t}}\right)^{1-\eta(1-\sigma)}\left(\frac{1-l_{t}}{1-l_{t+1}}\right)^{(1-\eta)(1-\sigma)}\left(\frac{a_{t+1} l_{t+1}}{a_{t} l_{t}}\right)^{1-\eta(1-\sigma)}\left(\frac{\tilde{\tau}_{t}}{\tilde{k}_{t}}\right)^{1-\theta}}{\theta \alpha \tilde{k}_{t+1}^{\alpha-1}+\left(\frac{\tilde{\tau}_{t+1}}{\tilde{k}_{t+1}}\right)^{1-\theta}\left\{(1-\theta)\left(\frac{\tilde{i}_{t+1}}{\tilde{k}_{t+1}}\right)^{\theta}+1-\delta\right\}}=w i t r_{t}
\end{gathered}
$$




$$
\frac{\frac{1}{\beta}\left(\frac{\tilde{c}_{t+1}^{*}}{\tilde{c}_{t}^{*}}\right)^{1-\eta(1-\sigma)}\left(\frac{1-l_{t}^{*}}{1-l_{t+1}^{*}}\right)^{(1-\eta)(1-\sigma)}\left(\frac{a_{t+1}^{*} l_{t+1}^{*}}{a_{t}^{*} l_{t}^{*}}\right)^{1-\eta(1-\sigma)}\left(\frac{\tilde{\tau}_{t}^{*}}{\tilde{k}_{t}^{*}}\right)^{1-\theta}}{\theta \alpha\left(1-g_{t+1}^{*}\right) \tilde{k}_{t+1}^{* \alpha-1}+\left(\frac{\tilde{\tau}_{t+1}^{*}}{\tilde{k}_{t+1}^{*}}\right)^{1-\theta}\left\{(1-\theta)\left(\frac{\tilde{\tau}_{t+1}^{*}}{\tilde{k}_{t+1}^{*}}\right)^{\theta}+1-\delta\right\}}=\operatorname{trr}_{t}^{*}
$$

In defining these wedges we have transformed the model into stationary form by expressing all variables (except $l$ and $l^{*}$ ) in per capita efficiency units of labor: $\tilde{x}=\frac{X}{a N l}$. The stationary representation will be useful later when we simulate the model. Note that the measurement of the wedges is not dependent on whether or not we transform the model into stationary form.

Along with the wedges in the first order conditions there are two productivity wedges as well (measured in labor augmenting form):

$$
\begin{aligned}
& A_{t}=a_{t}^{1-\alpha}=\frac{Y_{t}}{K_{t}^{\alpha}\left(N_{t} l_{t}\right)^{1-\alpha}} \\
& A_{t}^{*}=a_{t}^{* 1-\alpha}=\frac{Y_{t}^{*}}{K_{t}^{* \alpha}\left(N_{t}^{*} l_{t}^{*}\right)^{1-\alpha}}
\end{aligned}
$$

To measure these wedges we use annual data for the G7 countries from 1970-2004. Our data comes from the OECD. We divide up the G7 countries into two groups: Home (USA) and Foreign (G6: Britain, Germany, France, Italy, Canada and Japan). We construct aggregate Foreign variables by constructing a weighted sum of the corresponding variables for each constituent country. The data appendix at the end describes all the variables and their definitions (to be added).

Figures 1 - 4 plot the measured wedges during the sample period. We normalize all wedges to unity in 1970. Hence all the wedges start at unity. The wedges for the US are in blue while the G6 wedges are in red.

Some features of these measured wedges are noteworthy. Figure 1 shows that while the wedge in the optimal risk sharing condition in 2004 was only 5 percent above its level in 1970, it has gone through two distinct phases. Between 1970 and 1990 the wedge worsened significantly with the wedge in 1990 being about 22 percent higher relative to its 1970 level. Since 1990 however, the risk sharing wedge has declined secularly. Since this wedge is the US to G6 ratio of the marginal utility of consumption, the pattern says roughly that between 1970 and 1990 some factors 
Figure 1: Risk-sharing wedge: ratio of marginal utilities

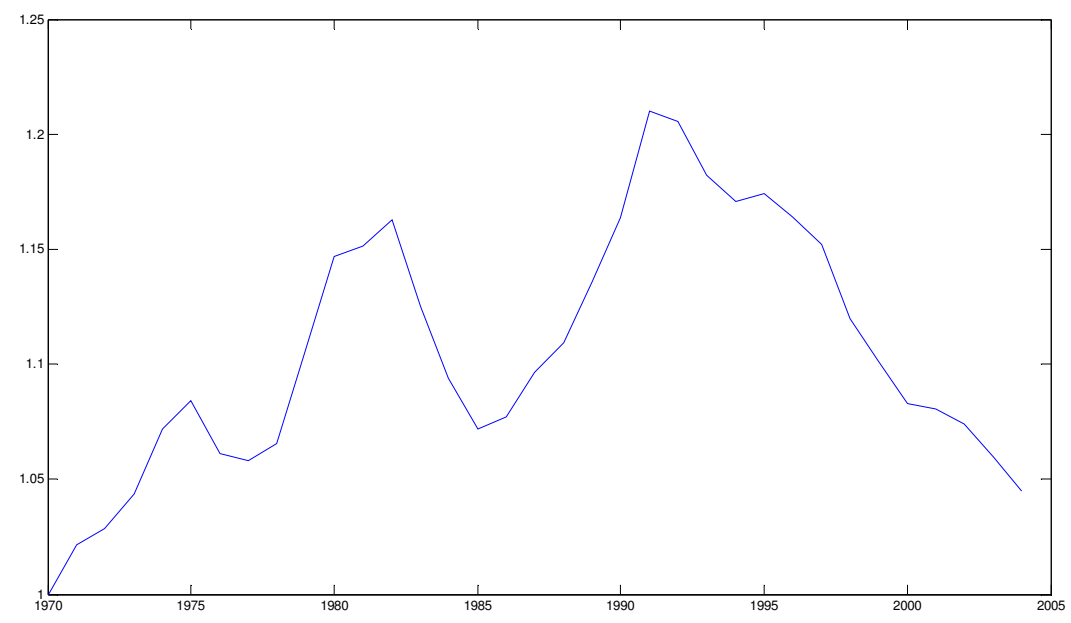

Figure 2: Intratemporal labor-leisure allocation wedge

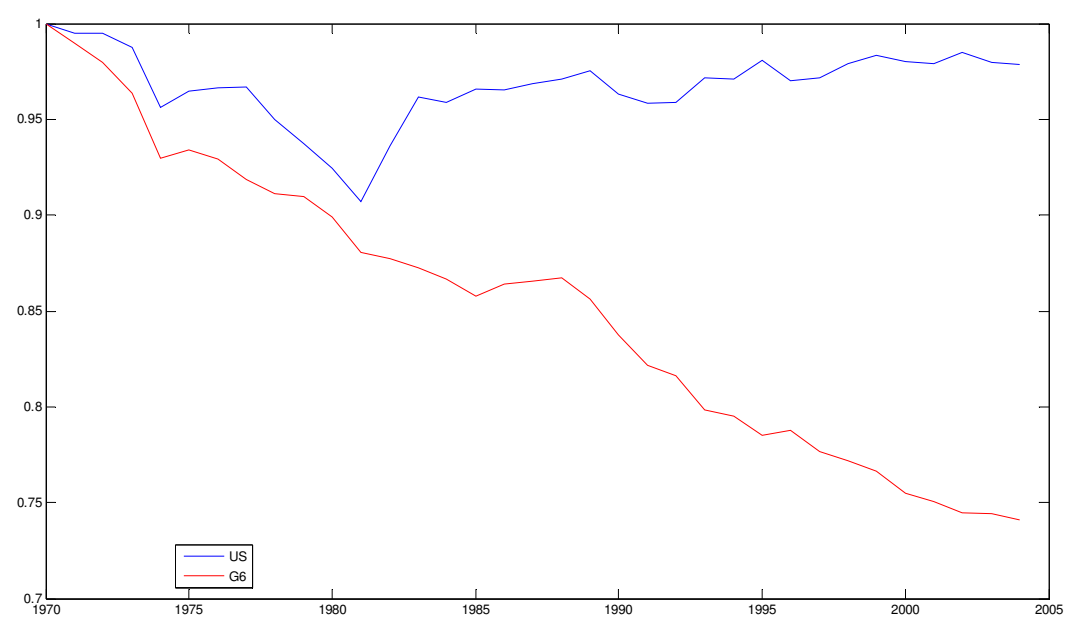


Figure 3: Intertemporal Euler wedge

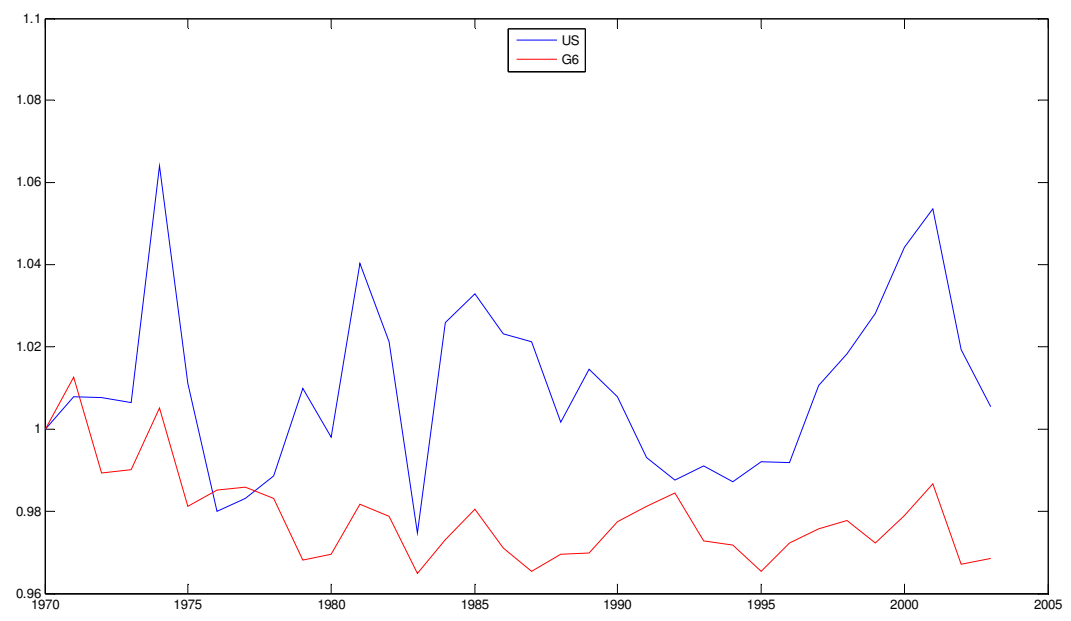

Figure 4: Productivity wedge

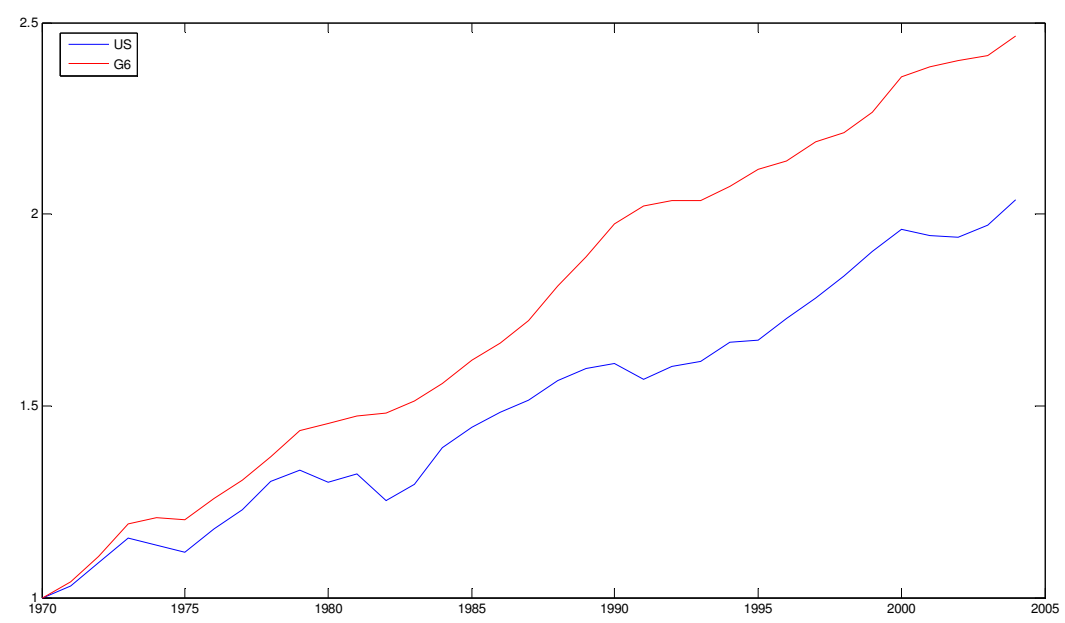


raised G6 consumption relative to US consumption as compared to the planners benchmark of full risk-sharing. Contrarily, from 1990 the wedge starting declining back toward its 1970 level.

Figure 2 shows that the wedge in the condition determining the optimal labor-leisure allocation moved very differently in the US and the rest of the G7. While this wedge declined in both regions during this period, the decline was much sharper in the G6 where it fell almost 25 percent during this period. Clearly, some factors have secularly reduced G6 labor supply below the levels implied by the frictionless planning benchmark. This is consistent with some of the recent work of Prescott (2004). The wedge in the intertemporal Euler equation doesn't show much movement in either region during this period (Figure 3). Lastly, Figure 4 shows that average total factor productivity growth in the G6 was marginally higher (2.7 percent per year) than in the US (2.1 percent per year) during this period. We should note that due to the normalization of the data to the 1970 level, the figure masks the fact that the level of productivity was higher in the US throughout.

\section{Accounting}

The movements in the measured values of the wedges that we reported above, while informative, are an incomplete description of the contribution of the different distortions to the actual path of the current account of these two regions. In particular, what one would like is to measure the individual contribution of each of these wedges to the actual path followed by the economy. An approach to such an exercize has been formalized in recent work by Chari, Kehoe and McGrattan (2004). ${ }^{2}$ The methodology is simple. The first step is to simulate the model by feeding in all the measured wedges simultaneously and calibrating the model to ensure that the simulated time series of the variables in the model reproduces the data exactly. This step implies that all the wedges can jointly account for the observed sample path.

The next step is to conduct counterfactual exercises by feeding in the wedges, both individually

\footnotetext{
${ }^{2}$ An implementation of this methodology to the case of India can be found in Lahiri and Yi (2005).
} 
and in combinations. Comparing the simulated series fom each counterfactual exercise with the actual data series enables one to assess the relative contributions of each wedge (and their combinations). This process allows the researcher to quantitatively determine which wedge (or wedges), amongst all the measured distortions of the model, is key to understanding the time series behavior of the economy during the period under study. Once the key wedges are identified it allows one to assess the qualitative and quantitative plausibility of candidate "deep" models which attempt to explain the time series behavior of the economy during the period under study.

The model has eight endogenous variables: $c, c^{*}, l, l^{*}, k, k^{*}$. Hence we need eight equations to solve the model. Five these are given by equations 9-13. To complete the system we use the two capital accumulation equations and the aggregate resource constraint:

$$
\begin{gathered}
n_{t}\left(1-g_{t}\right) F\left(k_{t}, a_{t} l_{t}\right)+n_{t}^{*}\left(1-g_{t}^{*}\right) F\left(k_{t}^{*}, a_{t}^{*} l_{t}^{*}\right)=\left[n_{t}\left(c_{t}+i_{t}\right)+n_{t}^{*}\left(c_{t}^{*}+i_{t}^{*}\right)\right] w r c_{t}, \\
\left(1+\gamma_{N}\right) k_{t+1}=k_{t}\left[\left(\frac{i_{t}}{k_{t}}\right)^{\theta}+1-\delta\right] \\
\left(1+\gamma_{N}^{*}\right) k_{t+1}^{*}=k_{t}^{*}\left[\left(\frac{i_{t}^{*}}{k_{t}^{*}}\right)^{\theta}+1-\delta\right]
\end{gathered}
$$

$\gamma_{N}$ denotes the growth rate of population at home while $n=N /\left(N+N^{*}\right)$ is the home share of world population. Correspondingly, $n^{*}=(1-n)$.

Note that in order to make this two-country model account for the data we have made an adjustment to the aggregate resource constraint. Since the G7 is not a closed economy, we must account for net imbalances with the rest of the world. Thus we have introduced a wedge in the resource constraint. This wedge measures net exports from the G7 (US plus G6) to the rest of the world (ROW). Hence, if $w r c>1$ then there are positive net exports from the G7 to the ROW. On the other hand, if $w r c<1$ then net exports from the G7 are negative. Figure 3 shows the measured resource constraint wedge. The Figure indicates that for most of the sample period, G7 net exports were positive and growing. Beginning in the late 1990's however, there was a precipitous drop in the $w r c$, continuing to the end of our sample data. Lastly, also note that there 
Figure 5: Resource constraint wedge

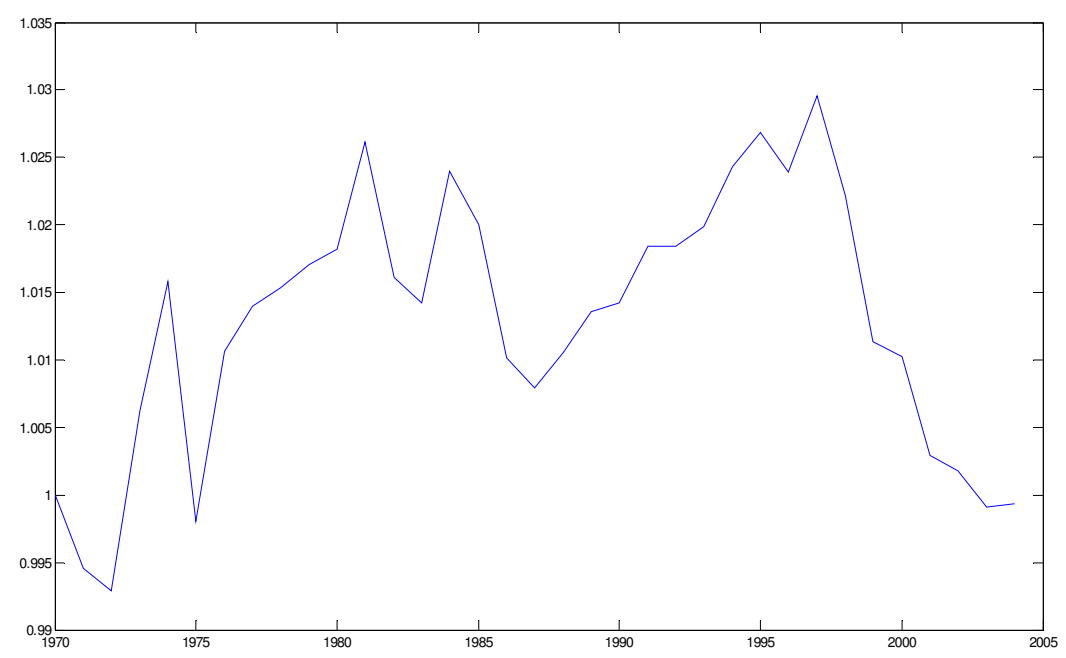

are no wedges in the two capital accumulation equations (17 and 18). This is because we generate the capital stock data for both regions using these equations. Hence, these two equations must hold exactly.

The system has ten exogenous variables: the five wedges in the first order conditions, the resource constraint wedge, the two productivity wedges, the two government spending wedge, and the two population processes. In order to make the simulated model fit the data from 1970 to 2004 exactly we need to make a few additional assumptions. First, since this is an infinite horizon model, we have to take a stand on the values of the wedges from 2005 and beyond. We assume that the Euler equation wedges witr and witr* both equal one from 2004 onward (recall that our data ends in 2004, hence the euler equation for 2004 necessarily involves making an assumption about 2005). We cannot have a steady state in this model unless this intertemporal wedge is unity. Second, we freeze forever all the other wedges in the first order conditions at their 2004 levels.

Third, in order to have a steady state in this model we need the steady state productivity growth and population growth to be identical in Home and Foreign. Hence, from 2005 onward we 
Figure 6: Data accounting with all wedges

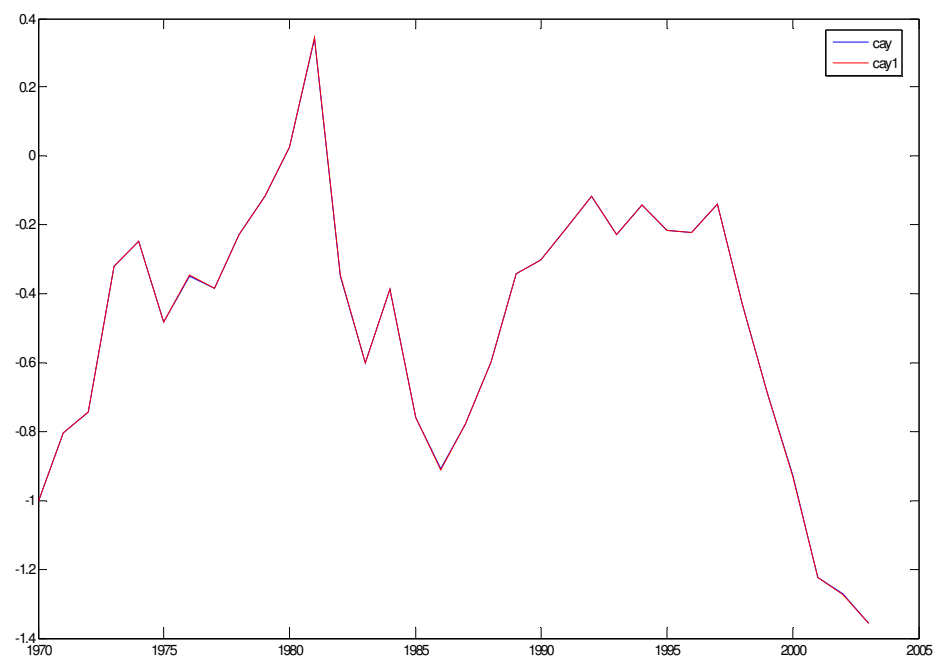

freeze the ratio of US/G6 productivity and US/G6 population at their 2004 levels. We then choose the common productivity growth, population growth and the long run output shares of government spending in Home and Foreign, $s$ and $s^{*}$, to match the 2004 levels of $\tilde{k}, \tilde{k}^{*}, \tilde{c}$ and $\tilde{c}^{*}$. We solve the system of eight equations using a non-linear equation solver subject to the additional assumption that steady state is attained in 300 periods. Once the solutions are derived, we compute the current account of each region by ubtracting total domestic absorption from output.

We start by plotting the US current account in the data and the simulated current account (as a share of GDP) series from the model with all the wedges in Figure 6. The figure shows that the wedges jointly account for the data perfectly. Note that we have normalized the current account series by the absolute value 1970 level. Hence, the plotted series starts from -1 (the USA ran a current account deficit in 1970).

In Figures - we plot the current account response to five counterfactual exercises. In particular, these figures plot the US current account response of the model to one measured wedge at a time while holding all the other wedges constant at their 1970 levels. Figure 7 plots the simulated 
Figure 7: Response to the risk sharing wedge

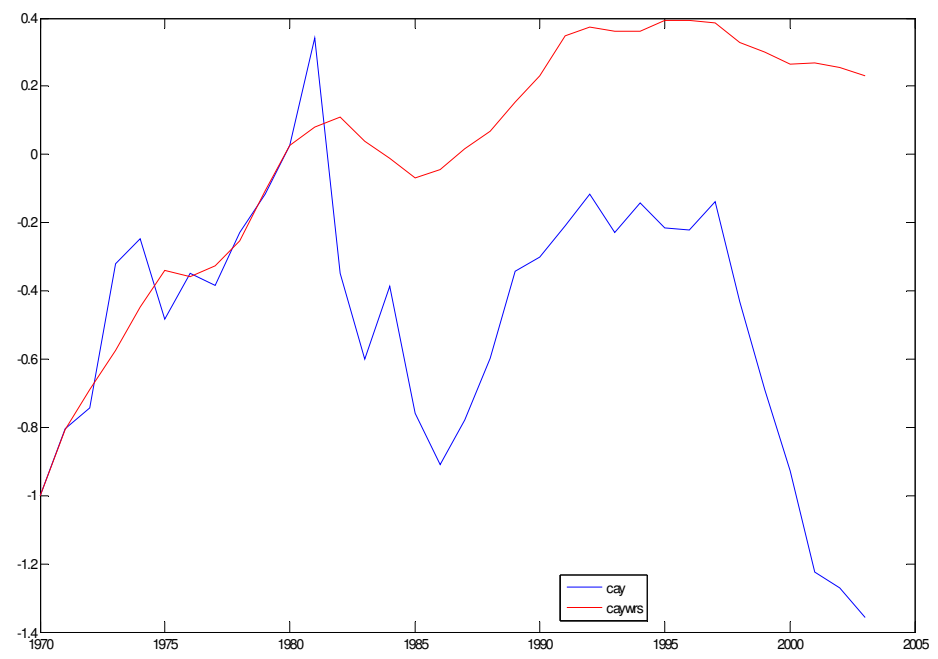

current account response of the model to the measured wedge in the risk sharing condition only. The figure shows that the risk sharing wedge does a fairly good job in explaining the US current account till about 1980 but fails to quantitatively pick up the huge current account deterioration after that. However, the simulated series does mimic the data qualititatively.

Figure 8gives the current account response to the wedges in the optimal labor-leisure allocation condition in the US and the G6. The picture shows that the labor-leisure wedge does reasonably well till 1980 but thereafter misses the movements in the US current account both qualitatively and quantitatively.

Figure 9 plots the current account response to the intertemporal euler wedges. The exercise suggests that if these intertemporal wedges had been the only wedges hitting the economy over the last 35 years, the US current account deficit would have been a lot higher than what we have seen. However, the figure also reveals that the simulated current account series generally moves in the opposite direction to that in the data. Thus, the simulated series shows a significant improvement in the current account since the late 1990s even though this is precisely the period when the US 
Figure 8: Response to the labor-leisure allocation wedge

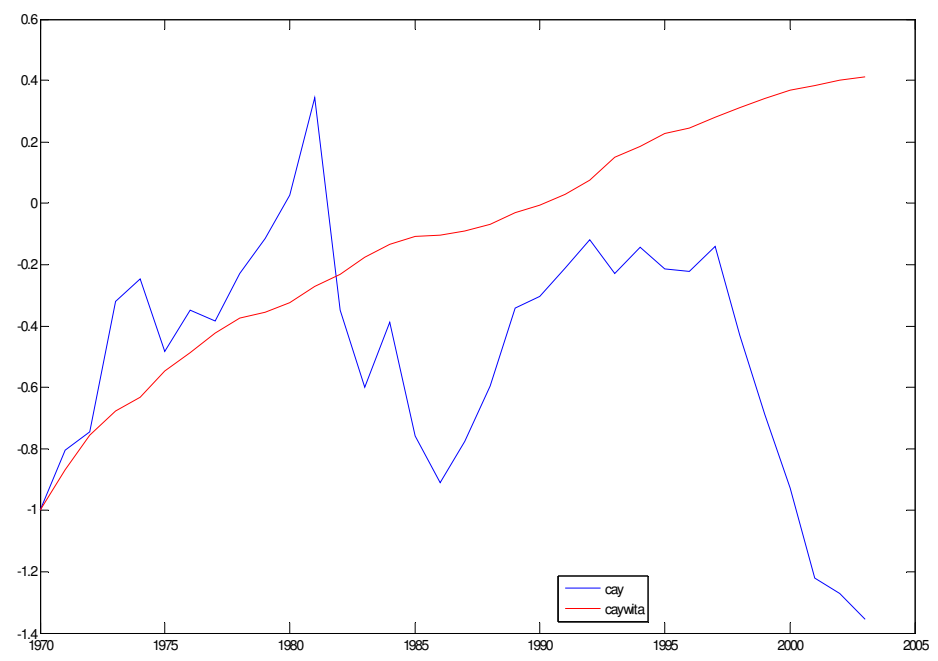

current account has gone into a sharp deterioration. A similar inverse movement can be seen in the period between 1970 and 1985. Clearly, the euler wedges perform poorly in terms of explaining the observed US current account movements.

Figure 10 shows the simulated current account response to the productivity wedges. The simulated current account series tracks the actual data series reasonably well throughout the sample period except for the late 1980s and the period since the late 1990s. For the late 1980s it fails to pick up the sharp improvement in the current account while for the last period, the simulated series fails to quantitatively reproduce the sharp worsening of the US current account (even though it does so qualitatively).

Based on the results from feeding in the wedges individually, we conclude that the two wedges that appear to be most significant are the productivity wedges and the risk sharing wedge. To study their joint impact, we now plot the current account response of the US economy when these two wedges are introduced jointly while holding all the other wedges at their 1970 levels. Figure 11 plots the result. It is clear that the simulated current account series tracks the data very well. 
Figure 9: Response to the Euler wedge

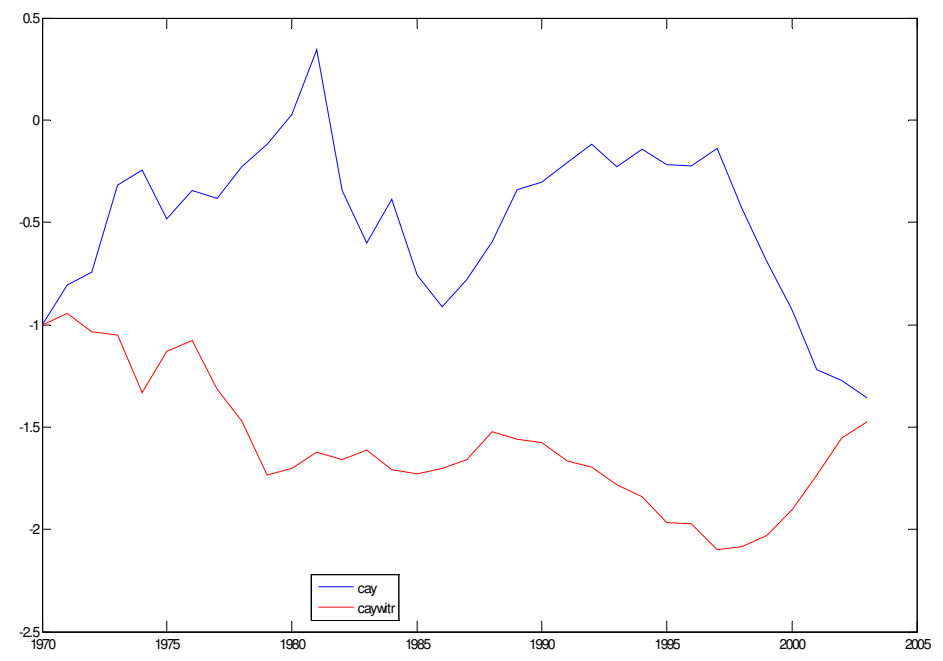

Figure 10: Response to productivity wedges

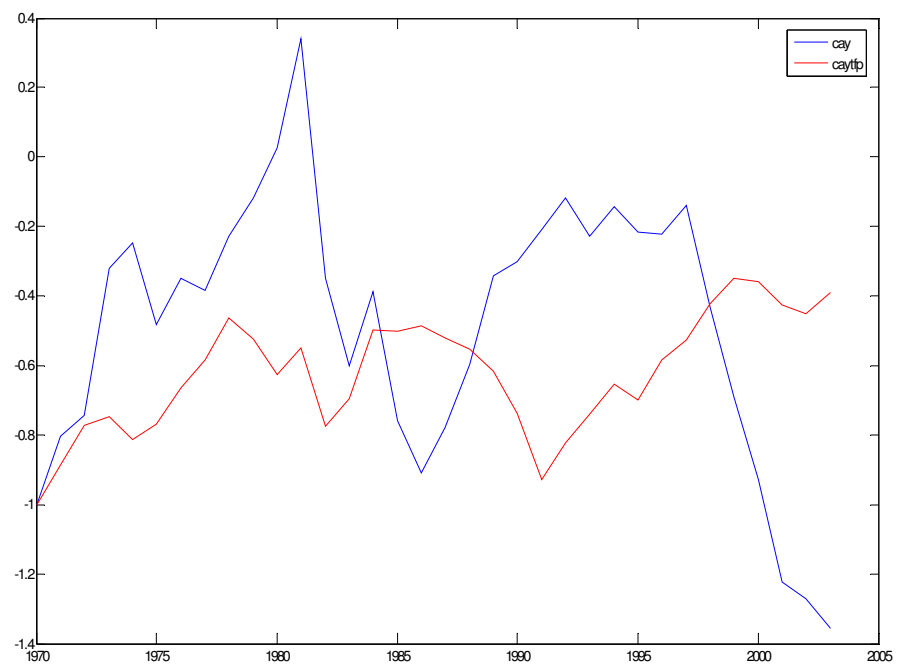


Figure 11: Response to the TFP and risk sharing wedge

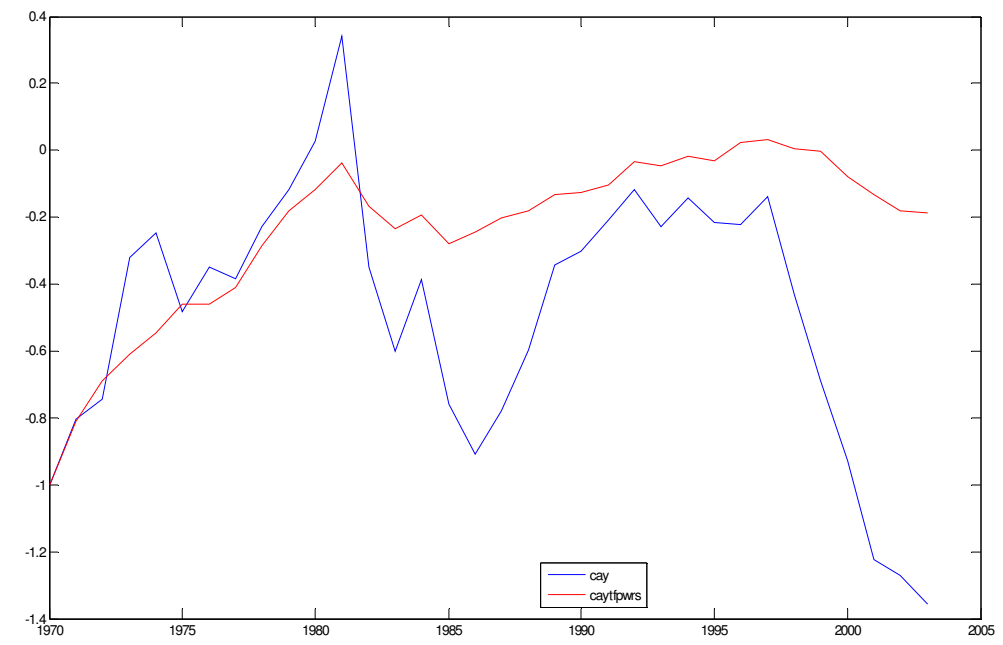

The only phase in which it fails quantitatively is the period since 2000 . The artificial series, does show a current account deterioration but the magnitude is much smaller than in the data.

One key feature of this methodology is the interaction between separate wedges. While two wedges separately may not do well in explaining the current account, in combination they may do so. Figure 12 provides an example. This Figure feeds the combination of the wedge to the intertemporal Euler equations and the risk sharing wedge together into the model. As we saw above, the Euler wedges do not do a good job at all in explaining the current account, while the risk sharing wedge does a fair job but doesn't pick up the major turning points. However, in combination, Figure 12 shows that all the major turning points of the current account are adequately captured, as well as the magnitude of fluctuations, even the most recent post 1999 downturn.

These visual impressions are made concrete in Table 1 where we report the summary statistics of the current account to GDP ratio for the USA both in the data as well as each simulated current account/GDP series produced by the counterfactual exercises. As before, all the current account series are normalized by the absolute values of their 1970 levels. Thus, in the data, the normalized 
Figure 12: Response to Euler and Risk-sharing wedge

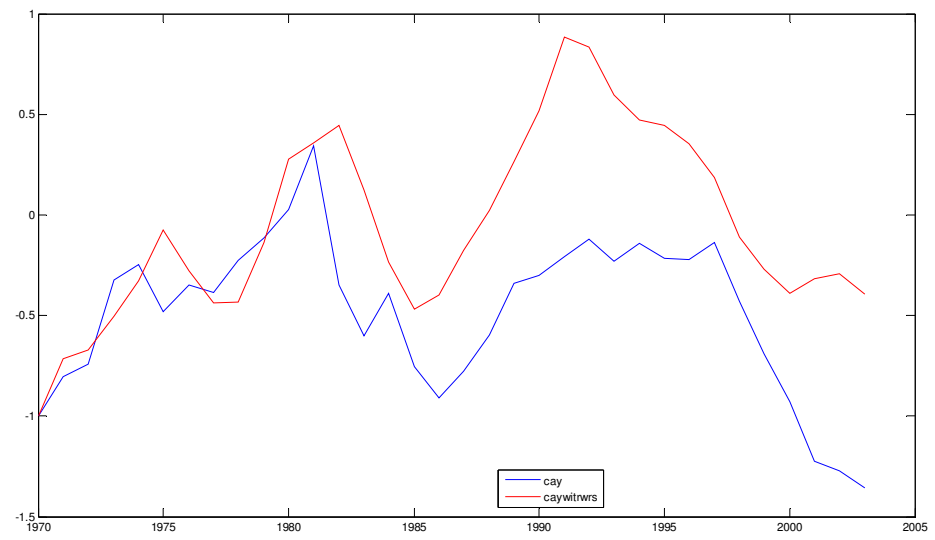

current account/GDP value in 1970 is -1 (since the US ran a deficit in 1970).

The Table shows that the productivity wedge (TFP wedge) generates a current account series with the lowest mean squared error (MSE) relative to the data as well as a mean level that is closest to the data. At the opposite end, the intertemporal euler wedge generates a counterfactual current account series that fails to match the data on virtually every dimension. Lastly, the artificial current account generated by the risk-sharing wedge has the highest correlation with the data.

The last two rows of the table show the statistics for the simulated current account series for the combination of the TFP and risk-sharing wedges and the Euler and risk-sharing wedge combination. Clearly, relative to the specifications where the wedges are introduced separately, both these wedge combinations improve the model's fit on all dimensions. In fact, amongst all possible combinations of two wedges at a time, these two combinations produces the best fit overall on the four dimensions that we report in the table. If one were to pick one of these two combinations, the choice would rest on which of these four dimensions one is interested in. Clearly, the Euler and roisk-sharing combination does extremely well in terms of the correlation of the simulated current account with the data. On the other hand, the TFP and risk-sharing wedge combination does better on the mean squared error and mean dimenions. 
Table 1. The US current account 1970-2004

\begin{tabular}{lllll}
\hline \hline & Mean & Std. dev. & MSE & Correlation \\
\cline { 2 - 5 } Data & -0.49 & 0.39 & & \\
TFP wedge & -0.62 & 0.17 & 0.23 & -0.27 \\
Euler wedge & -1.59 & 0.32 & 1.50 & -0.20 \\
Labor-leisure wedge & -0.13 & 0.39 & 0.47 & -0.15 \\
Risk-sharing wedge & 0 & 0.37 & 0.47 & 0.16 \\
Resource wedge & -0.16 & 0.34 & 0.36 & 0.04 \\
TFP + Risk-sharing & -0.24 & 0.25 & 0.21 & 0.30 \\
Euler + Risk-sharing & -0.05 & 0.46 & 0.32 & 0.62 \\
\hline \hline
\end{tabular}

\section{Some implications}

Two key features that emerged from the accounting exercise above were that (a) the productivity and risk-sharing wedges could jointly account for a significant part of the observed movement in the US current account over the last 35 years; (b) the intertemporal euler wedge appears to have little explanatory power for the observed current account dynamics. The facts that movements in the risk-sharing wedge appears to have been fairly important while movements in the euler wedge relatively unimportant can be used to deduce a key feature behind the observed dynamics.

The crucial feature that we would like to highlight is that the intertemporal euler wedges and the risk-sharing edges are related. To see how, consider an environment where there is a per-unit 
consumption tax $\phi_{t}$ in Home and $\phi_{t}^{*}$ in Foreign. Define

$$
\begin{aligned}
& \tilde{R}_{t+1} \equiv \frac{\theta \alpha \tilde{k}_{t+1}^{\alpha-1}+\left(\frac{i_{t+1}}{k_{t+1}}\right)^{1-\theta}\left\{(1-\theta)\left(\frac{i_{t+1}}{k_{t+1}}\right)^{\theta}+1-\delta\right\}}{\left(\frac{i_{t}}{k_{t}}\right)^{1-\theta}} \\
& \tilde{R}_{t+1}^{*} \equiv \frac{\theta \alpha \tilde{k}_{t+1}^{* \alpha-1}+\left(\frac{i_{t+1}^{*}}{k_{t+1}^{*}}\right)^{1-\theta}\left\{(1-\theta)\left(\frac{i_{t+1}^{*}}{k_{t+1}^{*}}\right)^{\theta}+1-\delta\right\}}{\left(\frac{i_{t}^{*}}{k_{t}^{*}}\right)^{1-\theta}}
\end{aligned}
$$

Using these definitions and the consumption tax characterization detailed above, it is easy to check that the euler wedges can be written as

$$
\begin{aligned}
\frac{1+\phi_{t}}{1+\phi_{t+1}} & =\text { witr }=\frac{u_{c}\left(c_{t}, 1-l_{t}\right)}{\beta \tilde{R}_{t+1} u_{c}\left(c_{t+1}, 1-l_{t+1}\right)} \\
\frac{1+\phi_{t}^{*}}{1+\phi_{t+1}^{*}} & =\text { witr }_{t}^{*}=\frac{u_{c}\left(c_{t}^{*}, 1-l_{t}^{*}\right)}{\beta \tilde{R}_{t+1}^{*} u_{c}\left(c_{t+1}^{*}, 1-l_{t+1}^{*}\right)}
\end{aligned}
$$

It is easy to check that the intertemporal and risk-sharing wedges can be combined to give

$$
\frac{w r s_{t}}{w r s_{t+1}}=\frac{w i t r_{t}}{w i t r_{t}^{*}} \frac{\tilde{R}_{t+1}}{\tilde{R}_{t+1}^{*}}
$$

The first-order conditions for the planner's problem also imply that $\tilde{R}_{t}=\tilde{R}_{t}^{*}$ for all $t .^{3}$ But this is the source of another wedge. Hence, the movement in the risk-sharing wedge over time is a combination of movements in the intertemporal euler wedge and movements in the ratio of the real interest rate across the two regions. The accounting exercise above showed that while the movements in the risk-sharing wedge is important, the euler wedges are not. The expression above reveals that the importance of the risk-sharing wedge must, therefore, be due to differential movements in the real interest rates in the two regions. We also saw that the risk-sharing wedge increased over the first half of the sample period and then declined back toward its original level

\footnotetext{
${ }^{3}$ Note that this always true in the undistorted environment that we wrote down earlier. In the environment with taxes, the planner's problem would have to be rewritten and a pseudo planning problem where the planner takes the taxes as given. Kehoe, Levine and Romer (1992) show that every solution of such a pseudo-planning problem can be decentralized as a competitive equilibrium with an appropriate choice of the initial wealth distribution. Crucially, the pseudo planning problem would also imply $\tilde{R}=\tilde{R}^{*}$.
} 
during the second half. The decomposition above suggests that this movement primarily reflects a relative increase in real interest rates in the US during the first half and the opposite movement during the second half.

\subsection{Conclusions}

To be added. 


\section{References}

[1] Chari, V. V., Patrick J. Kehoe, and Ellen McGrattan, 2004, "Business Cycle Accounting," NBER Working Paper 10351.

[2] Caballero, Ricardo, and Pierre-Olivier Gourinchas, 2005, "An Equilibrium Model of Global Imbalances and Low Interest Rates," mimeo UC Berkeley.

[3] Cole, Harold L., and Lee Ohanian, 2002, "The U.S. and U.K. Great Depressions through the Lens of Neoclassical Growth Theory," American Economic Review 92 (2), 28-32.

[4] Cole, Harold L., and Lee Ohanian, 2004, "New Deal Policies and the Persistence of the Great Depression: A General Equilibrium Analysis," Journal of Political Economy 112 (4), 779-816.

[5] Engel, Charles, and John Rogers, 2005, "The US Current Account Deficit and the Expected Share of World Output," mimeo University of Wisconsin.

[6] Kehoe, Timothy J., David K. Levine and Paul M. Romer, 1992. "On Characterizing Equilibria of Economies with Externalities and Taxes as Solutions to Optimization Problems", Economic Theory, 2, 43-68.

[7] Lahiri, Amartya, and Kei-Mu Yi, 2005, "A Tale of Two States: Maharashtra and West Bengal," mimeo University of British Columbia.

[8] Mulligan, Casey B., 2002, “A Dual Method of Empirically Evaluating Dynamic Competitive Equilibrium Models with Market Distortions, Applied to the Great Depression and World War II." NBER Working Paper 8775.

[9] Prescott, Edward C., 2004, "Why Do Americans Work So Much More Than Europeans?" Federal Reserve Bank of Minneapolis Quarterly Review 28 (1), 2-13. 